Psychological Medicine

http://journals.cambridge.org/PSM

PSYCHOLOGICAL

Additional services for Psychological Medicine:

Email alerts: $\underline{\text { Click here }}$

Subscriptions: $\underline{\text { Click here }}$

Commercial reprints: $\underline{\text { Click here }}$

Terms of use : $\underline{\text { Click here }}$

\title{
Facial emotion recognition in adolescents with psychotic-like experiences: a school-based sample from the general population
}

S. Roddy, L. Tiedt, I. Kelleher, M. C. Clarke, J. Murphy, C. Rawdon, R. A. P. Roche, M. E. Calkins, J. A. Richard, C. G. Kohler and M. Cannon

Psychological Medicine / Volume 42 / Issue 10 / October 2012, pp 2157 - 2166

DOI: 10.1017/S0033291712000311, Published online: 28 February 2012

Link to this article: http://journals.cambridge.org/abstract S0033291712000311

How to cite this article:

S. Roddy, L. Tiedt, I. Kelleher, M. C. Clarke, J. Murphy, C. Rawdon, R. A. P. Roche, M. E. Calkins, J. A. Richard, C. G. Kohler and M. Cannon (2012). Facial emotion recognition in adolescents with psychotic-like experiences: a school-based sample from the general population. Psychological Medicine, 42, pp 2157-2166 doi:10.1017/S0033291712000311

Request Permissions : $\underline{\text { Click here }}$ 


\title{
Facial emotion recognition in adolescents with psychotic-like experiences: a school-based sample from the general population
}

\author{
S. $\operatorname{Roddy}^{1 *}$, L. Tiedt ${ }^{1}$, I. Kelleher ${ }^{1}$, M. C. Clarke ${ }^{1}$, J. Murphy ${ }^{1}$, C. Rawdon ${ }^{2}$, R. A. P. Roche ${ }^{2}$, \\ M. E. Calkins ${ }^{3}$, J. A. Richard ${ }^{3}$, C. G. Kohler ${ }^{3}$ and M. Cannon ${ }^{2,4}$ \\ ${ }^{1}$ Department of Psychiatry, Royal College of Surgeons in Ireland, Dublin, Ireland \\ ${ }^{2}$ School of Psychology, National University of Ireland, Maynooth, Ireland \\ ${ }^{3}$ Department of Psychiatry, School of Medicine, University of Pennsylvania, Philadelphia, PA, USA \\ ${ }^{4}$ Department of Psychiatry, Beaumont Hospital, Dublin, Ireland
}

Background. Psychotic symptoms, also termed psychotic-like experiences (PLEs) in the absence of psychotic disorder, are common in adolescents and are associated with increased risk of schizophrenia-spectrum illness in adulthood. At the same time, schizophrenia is associated with deficits in social cognition, with deficits particularly documented in facial emotion recognition (FER). However, little is known about the relationship between PLEs and FER abilities, with only one previous prospective study examining the association between these abilities in childhood and reported PLEs in adolescence. The current study was a cross-sectional investigation of the association between PLEs and FER in a sample of Irish adolescents.

Method. The Adolescent Psychotic-Like Symptom Screener (APSS), a self-report measure of PLEs, and the Penn Emotion Recognition-40 Test (Penn ER-40), a measure of facial emotion recognition, were completed by 793 children aged 10-13 years.

Results. Children who reported PLEs performed significantly more poorly on FER $(\beta=-0.03, p=0.035)$. Recognition of sad faces was the major driver of effects, with children performing particularly poorly when identifying this expression $(\beta=-0.08, p=0.032)$.

Conclusions. The current findings show that PLEs are associated with poorer FER. Further work is needed to elucidate causal relationships with implications for the design of future interventions for those at risk of developing psychosis.

Received 5 April 2011; Revised 20 December 2011; Accepted 2 February 2012; First published online 28 February 2012

Key words: Adolescent, child, facial emotion recognition, psychotic symptoms, psychotic-like experience.

\section{Introduction}

Research shows that psychotic symptoms are relatively common in both the general adult community (Kessler et al. 1994; Kendler et al. 1996; Bijl et al. 1998; Johns et al. 2004) and child and adolescent populations (Poulton et al. 2000; Laurens et al. 2007). These symptoms, in the absence of psychotic disorder, are also termed psychotic-like experiences (PLEs; see Kelleher \& Cannon, 2011, for an overview of PLEs). A meta-analysis by van Os et al. (2009) reported a median prevalence of $5-8 \%$ for PLEs in the general population. Prevalence rates of PLEs in younger

* Address for correspondence: Dr S. Roddy, Department of Psychiatry, Royal College of Surgeons in Ireland, Education and Research Centre, Beaumont Hospital, Dublin 9, Ireland.

(Email: sarah.roddy@gmail.com) populations vary from $9 \%$ of schoolchildren aged 7 and 8 years (Bartels-Velthuis et al. 2010) to up to half of 9-12-year-olds reporting 'certain experience' of one or more PLEs (Laurens et al. 2007). Alemany et al. (2011) reported that, in a sample of 533 young people (mean age $=22.9$ years), more than $40 \%$ 'often' or 'almost always' experienced a PLE. The importance of PLEs is highlighted by the possibility that they might serve as markers for an increased risk of psychotic disorder later in adult life. Data from the Dunedin birth cohort study showed that children aged 11 years who reported psychotic symptoms were found to be at a 5- to 16-fold increased risk of schizophreniform disorder later in life (Poulton et al. 2000). In an Australian cohort study, Welham et al. (2009) showed that self-reported auditory hallucinations at 14 years were associated with increased risk for non-affective psychotic disorder at 21 years. Hanssen et al. (2005) found that, in a 
Dutch sample, $8 \%$ of those who experienced PLEs were clinically psychotic 2 years later. It is thought that these symptoms represent the less severe end of a continuum of psychosis (van Os et al. 2000). Indeed, several studies have demonstrated a continuum between the non-pathological subclinical phenotype and clinical psychosis, including shared risk factors such as childhood trauma (Kelleher et al. 2008), ethnicity (Laurens et al. 2008) and reduced performance on intelligence tests (Horwood et al. 2008) (for review see Kelleher \& Cannon, 2011).

Social cognition deficits have been widely documented in individuals with schizophrenia (Penn et al. 1997; Couture et al. 2006). One important component of social cognition that has been extensively studied in schizophrenia patients is the ability to recognize emotions in the faces of others (Mandal et al. 1998; Whittaker et al. 2001; Edwards et al. 2002; Hooker \& Park, 2002; Bolte \& Poustka, 2003; Kohler et al. 2003; Schneider et al. 2006; Pinkham et al. 2007; PomarolClotet et al. 2010). There are consistent findings of an impairment in facial emotion recognition (FER) in schizophrenia (for review see Kohler et al. 2010), and these deficits have been shown to be associated with abnormal neural activity ( $\mathrm{Li}$ et al. 2010). Given the established findings for FER deficits in schizophrenia, and in an attempt to gain insights into the earliest cognitive deficits in the developmental trajectory to psychosis, research has recently begun to investigate FER deficits in individuals who are at risk for this disorder.

Deficits in FER have been documented in those at genetic high risk (based on family history) (McCown et al. 1988; Kee et al. 2004; Eack et al. 2010) and in individuals who are at clinical or ultra-high risk (UHR) for schizophrenia, based on criteria for an At-Risk Mental State (ARMS) or prodrome (Addington et al. 2008). Research has also examined the relationship between FER deficits and schizotypal personality disorder (SPD). In one of the first such investigations, Poreh et al. (1994) examined FER among hypothetically schizotypic college men (defined by high scores on the perceptual aberration, magical ideation and schizotypy scales) and found that, relative to control participants, high-scoring participants made more errors in FER. This association was initially not replicated by Toomey \& Schuldberg (1995), who reported no significant association between FER and psychosisproneness (as indexed by measures of schizotypy) among a sample of university students. However, all subsequent studies reported deficits in FER that were associated with schizotypy or SPD (Mikhailova et al. 1996; Waldeck \& Miller, 2000; van 't Wout et al. 2004).

Recently, Germine \& Hooker (2011) found that FER was related to individual differences in psychosis-like characteristics in the normal population. In addition, Dickey et al. (2011) reported that participants with clinically diagnosed SPD (SCID-II) were slower and less accurate than healthy controls in identifying facial expressions. However, in the only previous study to directly examine FER in relation to PLEs, Thompson et al. (2011) reported that FER in 8-year-olds was not related to the reporting of PLEs 3 years later. Thus, the relationship between subclinical PLEs and FER is obscure. Differences in participant age are particularly important in the context of FER. For example, although it has been established that recognition of facial emotions emerges early (Barrera \& Maurer, 1981; Walker-Andrews, 1997), it is thought that full proficiency is not acquired before 10 years of age. Facial emotion processing abilities increase with age (Durand et al. 2007), thus the 8-year-olds in Thompson et al.'s study would have been substantially less accurate than the adult participants in some of the other studies. The current study aimed to further understanding of the association between FER and PLEs and involved a community sample of adolescents who reported PLEs.

\section{Method}

\section{Recruitment}

Ethical approval for this study was given by Beaumont Hospital Medical Research Ethics Committee. Thirteen large single- and mixed-sex state primary schools in North and West Dublin, Kildare and Meath were recruited for participation, with a total of 793 individuals taking part. The majority of participants were Irish (89.2\%), with small numbers from the UK $(2.4 \%)$ and other countries (8.4\%). Participants were recruited from the 5th $(n=328)$ and 6th classes $(n=465)$, the two most senior classes in the primary education system, and were aged 10-13 years $($ mean $=11.5$, s.D. $=0.66)$ : 10-year-olds $(n=37)$, 11-year-olds $(n=382), 12$-year-olds $(n=338)$ and 13-year-olds $(n=36)$. There were approximately equal numbers of each gender (female: $n=401$; male: $n=392$ ). The study team visited participating schools and presented a brief information session about adolescent brain development to students, who were then given consent forms to take home to their parents. On this form, parents were asked to tick a box to indicate consent for their children to complete questionnaires in their classrooms. Parents and children were informed that the study was about adolescent brain development. To ensure and maximize confidentiality, children were asked to complete the questionnaire without allowing other children to see their answers. A study researcher was present at all times and 
children were instructed to ask the researcher for clarification if there was anything that they did not understand.

\section{Questionnaires}

The Adolescent Psychotic-Like Symptom Screener (APSS; Kelleher et al. 2011) was used to assess a variety of psychotic symptoms in a brief period of time. This is a seven-item measure consisting of four questions from the Diagnostic Interview Schedule for Children (Poulton et al. 2000) and three additional questions, one each on visual hallucinations, delusions of control, and grandiosity. For each question, participants selected one of three possible responses: 'Yes, definitely' (scored 1), 'Maybe' (scored 0.5) or 'No, never' (scored 0). Total scores were summated for each participant, with higher scores indicating greater experience of psychotic symptoms. Kelleher et al. (2011) reported that, in a sample of 334 adolescents aged 11-13 years, this brief screening tool had good sensitivity and specificity in identifying young people who had psychotic symptoms that were subsequently identified by clinical interview.

The Penn Emotion Recognition-40 Test (Penn ER40 ; Gur et al. 2001) comprises 40 coloured photographs of adult faces (depicting individuals who differ in race and gender) expressing one of four basic emotions (sad, happy, angry, and scared) and also the 'no feeling' emotional expression (i.e. eight faces depicting each of these five expressions). Penn ER-40 is typically used as a computerized task; however, given that testing took place in a group setting (school classrooms), participants were administered a penciland-paper version of the test. A forced-choice format was used, where participants had to choose, by circling the correct option, among the labels 'happy', 'sad', 'angry', 'scared' or 'no feeling' for the presented face. Correct responses were scored as 1 and incorrect responses were scored as 0 , thus the highest total score possible was 40; higher scores indicated better facial emotion recognition. Additionally, individual subscale totals were calculated for each of the five emotional expressions, with a highest score possible of eight. The Penn ER-40 has demonstrated good test-retest reliability (Weiss et al. 2007).

The Hinting Task (Corcoran et al. 1995) is a simple theory of mind test where the participant is required to infer the intention behind veiled speech acts. Ten short vignettes describing an interaction between two characters along with an extract of their dialogue, which ends with one character dropping a hint to the other, are presented. Participants read through the vignettes and are asked what the character really meant by what he/she said. Participants were instructed to write their inferences down. An appropriate inference was scored 2 points. If a participant had difficulty, they were instructed to raise their hand and one of the study team provided them with further information about the story in the form of an even more obvious hint. A correct response at this stage was scored 1 point. Scores on this task range from 0 to 20, with higher scores indicating greater ability to derive the true meaning behind a character's speech. The task has good face validity (Corcoran \& Frith, 2003) and has been found to be sensitive to theory of mind deficits in several studies (Corcoran et al. 1995).

\section{Data analysis}

Analyses were conducted using Stata version 11.0 (Stata Corporation, 2011). Total scores on the Penn ER-40 and individual subscale scores for the five emotional expressions of the Penn ER-40 along with total scores on the APSS and the Hinting Task were used in analyses. Mean scores and standard deviations on the APSS, Penn ER-40 and Hinting Task were first reported. Independent-sample $t$ tests were used to determine whether there were age and gender differences in scores on the APSS, Penn ER-40 and Hinting Task. The Bonferroni correction was used to control for multiple comparisons with the Penn ER-40. Correlational analyses were used to examine the relationship between the Hinting Task and the Penn ER-40 and the APSS. Linear regression was used to investigate the relationship between the overall and subscale scores on the Penn ER-40, and the APSS total score (dependent variable). These analyses were repeated, controlling for potential confounders (age, gender and scores on the Hinting Task).

\section{Results}

\section{Participation rates}

In total, 1550 consent forms were distributed: 793 children completed the APSS (51.20\% consent rate), 748 children completed the Penn ER-40 and 409 completed the Hinting Task. Because of time constraints, slightly fewer participants completed the latter two measures and participants with missing data were not included in analyses. We have no information on the pupils who did not agree to take part in the study.

\section{The APSS}

The mean total score on the APSS was 1.71 (S.D. =1.53). Overall, $46.8 \%$ of the total sample answered 'Yes, definitely' to at least one item, 24.8\% answered 'Yes, definitely' to two or more items, and $14.1 \%$ answered 'Yes, definitely' to three or more items. Table 1 displays 
Table 1. The percentages of girls and boys in the 10-11 and 12-13 years age groups who responded ' Yes, definitely' to items on the APSS

\begin{tabular}{|c|c|c|c|c|c|}
\hline \multirow[b]{2}{*}{ APSS questionnaire items } & \multirow[b]{2}{*}{ Abbreviation } & \multicolumn{2}{|c|}{ Age $10-11$ years } & \multicolumn{2}{|c|}{ Age $12-13$ years } \\
\hline & & Girls & Boys & Girls & Boys \\
\hline $\begin{array}{l}\text { 1. Have you ever heard voices or sounds that no one } \\
\text { else can hear? }\end{array}$ & $\begin{array}{l}\text { Auditory } \\
\text { hallucinations }\end{array}$ & 29.9 & 20.1 & 23.0 & 19.8 \\
\hline $\begin{array}{l}\text { 2. Have you ever thought that people are following } \\
\text { you or spying on you? }\end{array}$ & Spying & 22.9 & 23.4 & 20.3 & 16.0 \\
\hline $\begin{array}{l}\text { 3. Have you ever seen things that other people could } \\
\text { not see? }\end{array}$ & Visual hallucinations & 18.7 & 13.7 & 10.7 & 12.3 \\
\hline $\begin{array}{l}\text { 4. Some people believe that their thoughts can be read } \\
\text { by another person. Have other people ever read } \\
\text { your mind? }\end{array}$ & Mind reading & 12.6 & 11.7 & 16.0 & 10.2 \\
\hline $\begin{array}{l}\text { 5. Have you ever had messages sent just to you through } \\
\text { TV or radio? }\end{array}$ & $\mathrm{TV} /$ radio & 9.8 & 10.7 & 11.2 & 13.4 \\
\hline $\begin{array}{l}\text { 6. Have you ever felt you were under the control of } \\
\text { some special power? }\end{array}$ & Controlled & 12.6 & 6.8 & 8.0 & 4.8 \\
\hline 7. Have you ever felt like you had extra special powers? & Grandiosity & 11.2 & 6.8 & 6.4 & 7.0 \\
\hline
\end{tabular}

APSS, Adolescent Psychotic-Like Symptom Screener.

the percentage of participants endorsing individual items on the APSS. The most common symptom reported by participants was auditory hallucinations.

Significant age differences emerged in participants' total scores $\left(t_{791}=2.27, p=0.023\right)$, with children in the $10-11$ age group $($ mean $=1.82$, S.D. $=1.53)$ scoring significantly higher than children in the 12-13 age group $($ mean $=1.58$, S.D. $=1.53)$. Significant gender differences also emerged $\left(t_{791}=-2.68, p=0.0075\right)$, with girls $($ mean $=1.86$, s.D. $=1.58)$ scoring significantly higher than boys $($ mean $=1.57$, s.D. $=1.47)$.

\section{Penn ER-40}

Overall, the mean number of faces correctly identified by the sample was 30.38 (s.D.=3.95). In the total sample, participants were best at identifying happy $($ mean $=7.60$, s.D. $=0.91)$ and no feeling faces $($ mean $=$ 6.56, S.D. $=1.57)$ and worst at identifying sad $($ mean $=4.91$, S.D. $=1.46)$ and angry faces (mean $=5.07$, S.D. $=1.50)$, with average scores for scared faces $(\mathrm{mean}=6.21$, S.D. $=1.58)$ falling between this range. Significant age and gender effects were observed with younger participants (10-11-year-olds) scoring higher on happy, sad and angry faces $\left(p^{\prime} s<0.014\right)$ and boys scoring better than girls at identifying angry expressions $(p=0.016)$.

\section{The Hinting Task}

The average score on the Hinting Task was 15.2 (S.D.=3.62). Significant gender and age differences were observed with girls scoring higher than boys $(p=0.001)$ and older participants scoring higher than younger participants $(p<0.01)$. There was no significant relationship between the Hinting Task and the APSS $(p=0.231)$. In terms of the Penn ER-40, the Hinting Task was significantly correlated with scores for sad faces $(p=0.031)$ only $\left(p^{\prime} \mathrm{s}>0.138\right)$.

\section{Associations between the Penn ER-40 and PLEs}

Table 2 shows results of the linear regression analyses for the Penn ER-40 and total scores on the APSS. Inverse associations were found between these scores, with two of these associations being statistically significant. Specifically, with regard to the relationship for (i) the total score on the Penn ER-40 $(\beta=-0.03$, $t_{748}=-2.00, p=0.046$ ) and (ii) the score for sad faces $\left(\beta=-0.08, t_{748}=-2.16, p=0.031\right)$, higher scores on the APSS were associated with lower scores on the Penn ER-40. There were no significant associations between children's APSS scores and scores on the Penn ER-40 for angry, fearful or happy faces $\left(p^{\prime} \mathrm{s}>0.186\right)$.

\section{Associations between the Penn ER-40 and PLES when adjusting for age, gender and the Hinting Task}

Given that age and gender differences were found for scores on both the Penn ER-40 and the APSS, and that the Hinting Task was significantly correlated with scores on sad faces, a further series of linear regression analyses was conducted to control for the influence of these variables on the results reported previously. These data are also presented in Table 2. First, for the overall sample, the results show that gender and age did not account for the significant relationships 
Table 2. Non-adjusted and adjusted standardized coefficients for the relationship between scores on the Penn ER-40 and the APPS

\begin{tabular}{|c|c|c|c|c|c|c|c|c|}
\hline \multirow{2}{*}{$\begin{array}{l}\text { Penn ER-40 } \\
\text { emotions }\end{array}$} & \multicolumn{4}{|c|}{ Non-adjusted scores } & \multicolumn{4}{|c|}{$\begin{array}{l}\text { Scores adjusted for participant age, gender and } \\
\text { the Hinting Task }\end{array}$} \\
\hline & $t$ & $\mathrm{df}$ & $\beta$ (S.E.) & $p$ value & $t$ & $\mathrm{df}$ & $\beta$ (S.E.) & $p$ value \\
\hline Total & -2.00 & $(1,746)$ & $-0.03(0.01)$ & 0.046 & -2.01 & $(4,407)$ & $-0.09(0.14)$ & 0.038 \\
\hline Happy & -0.092 & $(1,746)$ & $-0.06(0.06)$ & 0.358 & 0.021 & $(4,407)$ & $0.001(0.03)$ & 0.983 \\
\hline Sad & -2.16 & $(1,746)$ & $-0.08(0.04)$ & 0.031 & -1.98 & $(4,407)$ & $-0.10(0.05)$ & 0.047 \\
\hline Angry & -1.06 & $(1,746)$ & $-0.04(0.04)$ & 0.290 & 0.353 & $(4,407)$ & $0.45(0.16)$ & 0.725 \\
\hline Scared & -0.87 & $(1,746)$ & $-0.03(0.04)$ & 0.382 & 0.215 & $(4,407)$ & $0.01(0.05)$ & 0.830 \\
\hline No feeling & -0.80 & $(1,746)$ & $-0.03(0.04)$ & 0.422 & -0.639 & $(4,407)$ & $-0.03(0.05)$ & 0.523 \\
\hline
\end{tabular}

Penn ER-40, the Penn Emotion Recognition-40 Test; APPS, Adolescent Psychotic-Like Symptom Screener; df, degrees of freedom; S.E., standard error.

between the APSS and (i) the total score on the Penn ER-40 $\left(\beta=-0.03, t_{748}=-2.11, p=0.035\right)$ and (ii) the score for sad faces $\left(\beta=-0.08, t_{748}=-2.14\right.$, s.E. $=0.04$, $p=0.032)$. Second, with the subsample of participants $(n=409)$ who completed the Hinting Task along with the other measures, the addition of this measure to these analyses also did not account for the significant relationships between the APSS and (i) the total sore on the Penn ER-40 $\left(\beta=-0.09, t_{407}=-2.01, p=0.038\right)$ and (ii) the score for sad faces $\left(\beta=-0.10, t_{407}=-1.98\right.$, S.E. $=0.04, p=0.047)$. As is evident in Table 2 , controlling for these variables did not significantly affect the relationship between APSS scores and happy, scared or no feeling emotional expressions on the Penn ER-40.

\section{Discussion}

In the current study we found that adolescents who report PLEs had poorer ability to correctly identify facial emotional expressions. These findings were independent of the participants' age and gender. Analyses with a subsample of participants who had completed a theory of mind test also showed that the association between PLEs and FER was robust. These findings seem to be driven by a particular difficulty in the recognition of sad faces. Consistent findings have also been reported for the recognition of negative emotions in patients with schizophrenia, specifically fear (Gaebel \& Wolwer, 1992), sadness (Gaebel \& Wolwer, 1992; Kohler et al. 2003) and anger (Pinkham et al. 2003). It is important to note that the current findings were observed with a sample of adolescents with an average age of 11.5 years. Of interest, Amminger et al. (2011) recently reported that a sample of youngsters (aged 13-25 years) at UHR (on the basis of family history and/or an ARMS) of psychosis were significantly worse than a group of healthy controls at recognizing both 'sad' and 'fear' emotional expressions. Thus, in combination, the findings of the latter study and the current investigation suggest that specific difficulties in FER may be apparent at a young age and before the full expression of psychotic illness. Detecting these deficits at such an early age in individuals who have not yet entered the period of risk for psychotic disorder has implications in terms of early detection and intervention. Importantly, these findings suggest that emotion recognition is related to vulnerability to psychosis in addition to psychotic disorder (Penn et al. 1997; Edwards et al. 2001; Philips \& Seidman, 2008).

There are several different ways that our findings may be related to the aetiology of vulnerability to psychosis. First, problems in FER may be on the causal pathway to psychosis; in other words, these difficulties themselves are a risk factor for the development of psychosis, consistent with the neurodevelopmental model of schizophrenia (Marenco \& Weinberger, 2000). Second, poor FER may be a consequence of experiencing PLEs. Third, both poor FER and PLEs may be outcomes of a common aberrant developmental trajectory that, in some individuals, will eventually lead to psychotic disorder. It is important to note that performance on the Penn ER-40 has been shown to be heritable in families with schizophrenia (Greenwood et al. 2007; Gur et al. 2007; Calkins et al. 2010). We cannot distinguish between these three hypotheses because we do not have temporal information about the association seen here. However, the fact that a recent prospective analysis found no association between emotion deficits at age 8 and PLEs at age 13 (Thompson et al. 2011) whereas we found a relationship between PLEs and FER at age 11.5 years (on average) suggests that poor FER may be a consequence of developing PLEs. Thus, further research will need to address this issue to determine whether problems in FER serve as an index of subsequent psychotic disorder or even as an indicator of a vulnerability to psychosis and to inform the design of 
future intervention. At the same time it is important to note that the number of individuals who reported PLEs was much greater than the number that would be expected to eventually develop psychosis (Poulton et al. 2000). Follow-up work with this sample at further stages along the developmental trajectory would help to refine the precise nature of the association between PLEs and FER and the predictive validity, of one or both of these variables, as markers of subsequent psychotic disorder.

In keeping with our findings, research with older samples has shown poor FER in individuals with SPD (e.g. Poreh et al. 1994; Mikhailova et al. 1996; Waldeck \& Miller, 2000) and in those at increased risk of schizophrenia (McCown et al. 1988; Kee et al. 2004; Addington et al. 2008; Eack et al. 2010) in addition to individuals with schizophrenia (Gaebel \& Wolwer, 1992; Mandal et al. 1998; Hooker \& Park, 2002; Kohler et al. 2003, 2010).

The discrepancy in findings between the current work and that of Thompson et al. (2011) could also be due to several other factors. The current study used the Penn ER-40 whereas Thompson et al. used the Diagnostic Analysis of Non-Verbal Accuracy (DANVA). Despite their established psychometrics (e.g. Nowicki \& Duke, 1994; Kohler et al. 2004), these measures differ significantly. For example, the Penn ER-40 was administered as a pencil-and-paper test in a group setting whereas the DANVA is a computerized task completed individually. Another factor is that the Penn ER-40 presented images of adult faces whereas the DANVA presented photographs of children. The presentation of expressions on adult versus child faces is particularly important in light of recent research by Hoehl et al. (2010), who showed that although children (mean age $=6.2$ years) displayed stronger amygdala activation in response to angry expressions on adult versus child faces, the converse was true for happy facial expressions. Thus, the presentation of expressions on child versus adult faces is an important variable to consider and one that research suggests interacts with the expression being presented to influence how the emotions are processed.

Another important issue, independent of the measures used across these studies, is that Thompson et al. (2001) measured FER prospectively at age 8 years and psychotic symptoms 3 years later, whereas in the current study both of these variables were assessed at the same time point when children were, on average, 11.5 years of age. As referred to in the introduction, processing of facial emotions emerges early (e.g. Barrera \& Maurer, 1981; Walker-Andrews, 1997), but full competency emerges much later at around 10 years of age (Simonian et al. 2001), with more specific skills, such as the recognition of negative emotions, not fully established until later in adolescence (Camras \& Allison, 1985). The inclusion of younger participants by Thompson et al. might account for their finding of no association between emotion recognition and psychotic symptoms.

\section{Strengths and limitations}

The current work has several strengths. For example, it involved a large sample of adolescents from the general population; as such, it represents one of very few studies to examine the relationship between PLEs and FER in early adolescence. It also used a valid measure of PLEs, which has been shown to provide good sensitivity and specificity in identifying young adolescents in the general population with psychotic symptoms identified at clinical interview (Kelleher et al. 2011). At the same time, a limitation of the current work, as described previously, was that it involved a pencil-and paper version of the Penn ER-40 when past research has used a computerized version of this measure (Kohler et al. 2003; Pinkham et al. 2008). However, the pencil-and paper version seemed to be sensitive in picking up poor FER and allowed us to access a larger sample than would have been possible with a computerized version. Future research is needed to establish the validity of this pencil-and paper version of the Penn ER-40 and to examine its relationship with performances on the computerized protocol.

A second limitation of this study is that there was a consent rate of $51.20 \%$. However, this is comparable to that reported in previous investigations of the mental health of a community sample of Irish adolescents aged 12-15 years (Lynch et al. 2004, 2006). At the same time, this rate is significantly better than those reported in some previous community-based studies involving samples of adolescents from other countries. For example, Yung et al. (2009) reported a 19.7\% consent rate with a community sample of Australian adolescents (mean age $=15.64$ years). Third, this study did not consider the misattribution of facial expressions. Recent research by van Rijn et al. (2011) suggests that the misattribution of facial expressions might be the potential cognitive mechanism contributing to social impairments that have been observed in adolescents at UHR for psychosis. Thus, future work with adolescents who report PLEs might benefit from investigating emotion misattribution scores; for example, comparing the misattribution scores of individuals who scored high and low on the APSS. It is also possible that ceiling effects were observed for some emotional expressions on the Penn ER-40. The mean number of happy (7.60), no feeling (6.56) and scared (6.21) faces correctly recognized (out of a 
possible 8) was fairly high. Thus, this task might have been relatively easy for young adolescents to complete. More difficult computerized tasks that vary the intensity of the emotional expression (e.g. the DANVA; Thompson et al. 2011) or tasks that morph neutral faces to emotional faces (e.g. Norton et al. 2009) could be used in future research.

The fact that no information about the temporality of the relationship between PLEs and FER was provided represents a necessary limitation of the current work. It remains to be seen whether children's experience of PLEs resulted in the observed poorer performance in FER or whether this poorer ability preceded PLEs. However, determining the temporality of the association is not straightforward, given that we do not know how early PLEs emerge in development and the possibility that both poor FER and PLEs are outcomes of a common underlying process. Further research will need to address this issue to determine whether poor FER can serve as an index of vulnerability to psychosis. Finally, although attempts were made to control for possible confounding variables, including participant age and gender and performance on a theory of mind task, it is possible that other factors, such as intelligence, social class, parental education and previous childhood psychiatric disorders, may have influenced the observed results. Future research could explore the effects of these variables on the relationship between PLEs and facial emotion processing.

\section{Acknowledgements}

This work was supported by a Clinician Scientist Award from the Health Research Board (Ireland) and a 2009 National Alliance for Research on Schizophrenia and Depression (NARSAD) Essel Foundation Independent Investigator Award to M. Cannon. L. Tiedt was supported by a Health Research Board (Ireland) Summer Studentship. The research leading to these results has received funding from the European Community's Seventh Framework Programme under grant agreement no. HEALTH-F22010-241909: project European network of National Schizophrenia Networks Studying Gene-Environment Interactions (EU-GEI). We thank L. Power for her help in scoring the questionnaires. We thank the children and their parents for participating in the study and the teachers, principals and school secretaries for their help with this project.

\section{Declaration of Interest}

None.

\section{References}

Addington J, Penn D, Woods SW, Addington D, Perkins DO (2008). Facial affect recognition in individuals at clinical high risk for psychoses. British Journal of Psychiatry 192, 67-68.

Alemany S, Arias B, Aguilera M, Villa H, Moya J, Ibanez MI, Vossen H, Gasto C, Ortet G, Fananas L (2011). Childhood abuse, the BDNF-Val66Met polymorphism and adult psychotic-like experiences. British Journal of Psychiatry 199, 38-42.

Amminger GP, Schafer MR, Papageorgiou K, Klier CM, Schlogelhofer M, Mossaheb N, Werneck-Rohrer S, Nelson B, McGorry PD (2011). Emotion recognition in individuals at clinical high-risk for schizophrenia. Schizophrenia Bulletin. Published online: 21 March 2011. doi: 10.1093/schbul/sbr015.

Barrera M, Maurer D (1981). The perception of facial expressions by the three-month-old. Child Development $\mathbf{5 2}$, 203-206.

Bartels-Velthuis A, Jenner JA, van de Willigie G, van Os J, Wiersma D (2010). Prevalence and correlates of auditory vocal hallucinations in middle childhood. British Journal of Psychiatry 196, 41-46.

Bijl RV, Ravelli A, van Zessen G (1998). Prevalence of psychiatric disorder in the general population: results of the Netherlands Mental Health Survey and Incidence Study (NEMESIS). Social Psychiatry and Psychiatric Epidemiology 33, 587-595.

Bolte S, Poustka F (2003). The recognition of facial affect in autistic and schizophrenic subjects and their first-degree relatives. Psychological Medicine 33, 907-915.

Calkins ME, Tepper P, Gur RC, Ragland JD, Klei L, Wiener HW, Richard J, Savage RM, Allen TB, O'Jile J, Devlin B, Kwentus J, Ailyu MH, Bradford LD, Edwards N, Lyons PD, Nimgaonkar VL, Santos AB, Go RC, Gur RE (2010). Project among African-Americans to explore risks for schizophrenia (PAARTNERS): evidence for impairment and heritability of neurocognitive functioning in families of schizophrenic patients. American Journal of Psychiatry 167, 459-472.

Camras L, Allison K (1985). Children's understanding of emotional facial expressions and verbal labels. Journal of Nonverbal Behavior 9, 84-94.

Corcoran R, Frith CD (2003). Autobiographical memory and theory of mind: evidence of a relationship in schizophrenia. Psychological Medicine 33, 897-905.

Corcoran R, Mercer G, Frith C (1995). Schizophrenia, symptomatology and social inference: investigating theory of mind in people with schizophrenia. Schizophrenia Research 17, 5-13.

Couture SM, Penn DL, Roberts DL (2006). The functional significance of social cognition in schizophrenia: a review. Schizophrenia Bulletin 32 (Suppl. 1), S44-S63.

Dickey CC, Panych LP, Voglmaier MM, Niznikiewicz MA, Terry DP, Murphy C, Zacks R, Shenton ME, McCarley RW (2011). Facial emotion recognition and facial affect display in schizotypal personality disorder. Schizophrenia Research 131, 242-249. 
Durand K, Gallay M, Seigneuric A, Robichon F, Baudouin J-Y (2007). The development of facial emotion recognition: the role of configural information. Journal of Experimental Child Psychology 97, 14-27.

Eack SM, Mermon DE, Montrose DM, Miewald J, Gur RE Gur RC, Sweeney JA, Keshavan MS (2010). Social cognition deficits among individuals at familial high risk for schizophrenia. Schizophrenia Bulletin 36, 1081-1088.

Edwards J, Jackson HJ, Pattison PE (2002). Emotion recognition via facial expression and affective prosody in schizophrenia: a methodological review. Clinical Psychology Review 22, 789-832.

Edwards J, Pattison PE, Jackson HJ, Wales RJ (2001). Facial affect and affective prosody recognition in first-episode schizophrenia. Schizophrenia Research 48, 235-253.

Gaebel W, Wolwer W (1992). Facial expression and emotional face recognition in schizophrenia and depression. European Archives of Psychiatry and Clinical Neuroscience 242, 46-52.

Germine LT, Hooker CI (2011). Face emotion recognition is related to individual differences in psychosis-proneness. Psychological Medicine 41, 937-947.

Greenwood TA, Braff DL, Light GA, Cadenhead KS, Calkins ME, Dobie DJ, Freedman R, Green MF, Gur RE, Gur RC, Mintz J, Nuechterlein KH, Olincy A, Radant AD, Seidman LJ, Siever LJ, Silverman JM, Stone WS, Swerdlow NR, Tsaung DW, Tsaung MT, Turetsky BI, Schork NJ (2007). Initial heritability analyses of endophenotypic measures of schizophrenia: the consortium on the genetics of schizophrenia. Archives of General Psychiatry 64, 1242-1250.

Gur RC, Ragland JD, Moberg PJ, Turner TH, Bilker WB, Kohler C, Siegel SJ, Gur RE (2001). Computerized neurocognitive scanning: I. Methodology and validation in healthy people. Neuropsychopharmacology 25, 766-776.

Gur RE, Nimgaonkar VL, Almasy L, Calkins ME, Ragland JD, Pogue-Geile MF, Kanes S, Blangero J, Gur RC (2007). Neurocognitive endophenotypes in a multiplex multigenerational family study of schizophrenia. American Journal of Psychiatry 164, 813-819.

Hanssen M, Bak M, Bijl R, Vollebergh W, van Os J (2005). The incidence and outcome of subclinical psychotic experiences in the general population. British Journal of Clinical Psychology 44, 181-191.

Hoehl S, Brauer J, Brasse G, Striano T, Friederici AD (2010). Children's processing of emotions expressed by peers and adults: an fMRI study. Social Neuroscience 5, 543-559.

Hooker C, Park S (2002). Emotion processing and its relationship to social functioning in schizophrenia patients. Psychiatry Research 112, 41-50.

Horwood J, Salvi G, Thomas K, Duffy L, Gunnell D, Hollis C, Lewis G, Menezes P, Thompson A, Wolke D, Zammit S, Harrison G (2008). IQ and non-clinical psychotic symptoms in 12-year-olds: results from the ALSPAC birth cohort. British Journal of Psychiatry 193, 185-191.

Johns LC, Cannon M, Singleton N, Murray RM, Farrell M, Brugha T, Bebbington P, Jenkins R, Meltzer H (2004). Prevalence and correlates of self-reported psychotic symptoms in the British population. British Journal of Psychiatry 185, 298-305.

Kee KS, Horan WP, Mintz J, Green MF (2004). Do the siblings of schizophrenia patients demonstrate affect perception deficits? Schizophrenia Research 67, 87-94.

Kelleher I, Cannon M (2011). Psychotic-like experiences in the general population: characterizing a high-risk group for psychosis. Psychological Medicine 41, 1-6.

Kelleher I, Harley M, Lynch F, Arseneault L, Fitzpatrick C, Cannon M (2008). Associations between childhood trauma, bullying and psychotic symptoms among a schoolbased adolescent sample. British Journal of Psychiatry 193, 378-382.

Kelleher I, Harley M, Murtagh A, Cannon M (2011). Are screening instruments valid for psychotic-like experiences? A validation study of screening questions for psychotic-like experiences using in-depth clinical interview. Schizophrenia Bulletin 37, 362-369.

Kendler KS, Gallagher TJ, Abelson JM, Kessler RC (1996). Lifetime prevalence, demographic risk factors, and diagnostic validity of non-affective psychosis as assessed in a US community sample. The National Comorbidity Survey. Archives of General Psychiatry 53, 1022-1031.

Kessler RC, McGonagle KA, Zhao S, Nelson CB, Hughes M, Eshleman S, Wittchen H-U, Kendler KS (1994). Lifetime and 12-month prevalence of DSM-III-R psychiatric disorders in the United States: results from the National Comorbidity Survey. Archives of General Psychiatry 51, 8-9.

Kohler CG, Turner TH, Bilker WB, Bresinger CM, Siegel SJ, Kanes SJ, Gur RE, Gur RC (2003). Facial emotion recognition in schizophrenia: intensity effects and error pattern. American Journal of Psychiatry 160, 1768-1774.

Kohler CG, Turner TH, Stolar NM, Bilker WB, Brensinger CM, Gur RE, Gur RC (2004). Differences in facial expressions of four universal emotions. Psychiatry Research 128, 235-244.

Kohler CG, Walker JB, Martin EA, Healey KM, Moberg PJ (2010). Facial emotion perception in schizophrenia : a metaanalytic review. Schizophrenia Research 36, 1009-1019.

Laurens KR, Hodgins S, Maughan B, Murray RM, Rutter ML, Taylor EA (2007). Community screening for psychotic-like experiences and other putative antecedents of schizophrenia in children aged 9-12 years. Schizophrenia Research 90, 130-146.

Laurens KR, West SA, Murray RM, Hodgins S (2008). Psychotic-like experiences and other antecedents of schizophrenia in children aged 9-12 years: a comparison of ethnic and migrant groups in the United Kingdom. Psychological Medicine 38, 1103-1111.

Li H, Chan RCK, McAlonan GM, Gong Q (2010). Facial emotion processing in schizophrenia: a meta-analysis of functional neuroimaging data. Schizophrenia Bulletin 36, 1029-1039.

Lynch F, Mills C, Daly I, Fitzpatrick C (2004). Challenging times: a study to detect Irish adolescents at risk of psychiatric disorders and suicidal ideation. Journal of Adolescence 27, 441-451.

Lynch F, Mills C, Daly I, Fitzpatrick C (2006). Challenging times: prevalence of psychiatric disorders and suicidal 
behaviours in Irish adolescents. Journal of Adolescence 29, 555-573.

Mandal MK, Pandey R, Prasad AB (1998). Facial expressions of emotions and schizophrenia: a review. Schizophrenia Bulletin 24, 399-412.

Marenco S, Weinberger DR (2000). The neurodevelopmental hypothesis of schizophrenia: following a trail of evidence from cradle to grave. Developmental Psychopathology 12, 501-527.

McCown W, Johnson J, Austin S, Shefsky M (1988). Deficits in ability to decode facial affects in families of schizophrenics. Psychotherapy in Private Practice 6, 93-101.

Mikhailova ES, Vladimirova TV, Iznak AF, Tsusulkovskaya EJ, Sushko NV (1996). Abnormal recognition of facial expression of emotions in depressed patients with major depression disorder and schizotypal personality disorder. Biological Psychiatry 40, 697-705.

Norton D, McBain R, Holt DJ, Ongur D, Chen Y (2009). Association of impaired facial affect recognition with basic facial and visual processing deficits in schizophrenia. Biological Psychiatry 65, 1094-1098.

Nowicki Jr. S, Duke MP (1994). Individual differences in the nonverbal communication of affect: the Diagnostic Analysis of Nonverbal Accuracy Scale. Journal of Nonverbal Behavior 18, 9-35.

Penn DL, Corrigan PW, Bentall RP, Racenstein JM, Newman L (1997). Social cognition in schizophrenia. Psychological Bulletin 121, 114-132.

Philips LK, Seidman LJ (2008). Emotion processing in persons at risk for schizophrenia. Schizophrenia Bulletin 34, 888-903.

Pinkham AE, Penn DL, Perkins DO, Graham KA, Siegel M (2007). Emotion perception and social skill over the course of psychosis: a comparison of individuals 'at-risk' for psychosis and individuals with early and chronic schizophrenia spectrum illness. Current Opinion in Psychiatry

12, 198-212.

Pinkham AE, Penn DL, Perkins DO, Lieberman J (2003). Implications for the neural basis of social cognition for the study of schizophrenia. American Journal of Psychiatry 160, 815-824.

Pinkham AE, Sasson NJ, Calkins ME, Richard J, Hughett $P$, Gur RE, Gur RC (2008). The other-race effect in face processing among African American and Caucasian individuals with schizophrenia. American Journal of Psychiatry 165, 639-645.

Pomarol-Clotet E, Hynes F, Ashwin C, Bullmore ET, McKenna PJ, Laws KR (2010). Facial emotion processing in schizophrenia: a non-specific neuropsychological deficit? Psychological Medicine 40, 911-919.

Poreh AR, Whitman RD, Weber M, Ross T (1994). Facial recognition in hypothetically schizotypic college students: the role of generalized poor performance. Journal of Nervous and Mental Disease 182, 503-507.

Poulton R, Caspi A, Moffit TE, Cannon M, Murray R, Harrington HL (2000). Children's self-reported psychotic symptoms and adult schizophreniform disorder: a 15-year longitudinal study. Archives of General Psychiatry 57, 1053-1058.

Schneider F, Gur RC, Koch K, Backes V, Amunts K, Shah NJ, Bilker W, Gur RE, Habel U (2006).

Impairment in the specificity of emotion processing in schizophrenia. American Journal of Psychiatry 163, 442-447.

Simonian SD, Beidel D, Turner S, Berkes J, Long J (2001). Recognition of facial affect by children and adolescents diagnosed with social phobia. Child Psychiatry and Human Development 32, 137-145.

Stata Corporation (2011). STATA Statistical Software, Release 11. Stata Corporation: College Station, TX.

Thompson A, Sullivan S, Heron J, Thomas K, Zammit S, Horwood J, Gunnell D, Hollis C, Lewis G, Wolke D, Harrison G (2011). Childhood facial emotion and psychosis-like symptoms in a nonclinical population at 12 years of age: results from the ALSPAC birth cohort. Cognitive Neuropsychiatry 16, 136-157.

Toomey R, Schuldberg D (1995). Recognition and judgment of facial stimuli in schizotypal subjects. Journal of Communication Disorders 28, 193-203.

van Os J, Hanssen M, Bijl RV, Ravelli A (2000). Strauss (1969) revisited: a psychosis continuum in the general population? Schizophrenia Research 45, 11-20.

van Os J, Linscott RJ, Myin-Germeys I, Delespaul P, Krabbendam L (2009). A systematic review and meta-analysis of the psychosis-continuum: evidence for a psychosis-proneness-persistence-impairment model of psychotic disorder. Psychological Medicine 39, 179-195.

van Rijn S, Aleman A, de Sonneville L, Sprong M, Ziermens T, Schothorst $P$, van Engeland H, Swaab H (2011). Misattribution of facial expressions of emotion in adolescents at increased risk of psychosis: the role of inhibitory control. Psychological Medicine 41, 499-508.

van 't Wout M, Aleman A, Kessels RPC, Laroi F, Kahn RS (2004). Emotional processing in a non-clinical psychosis-prone sample. Schizophrenia Research 68, 271-281.

Waldeck TL, Miller LS (2000). Social deficits in schizotypal personality disorder. Psychiatry Research 93, 237-246.

Walker-Andrews AS (1997). Infants' perception of expressive behaviors: differentiation of multimodal information. Psychological Bulletin 121, 437-456.

Weiss E, Stadelmann E, Kohler CG, Brensinger C, Nolan KA, Oberacher H, Parson W, Pitterl F, Niederstatter $\mathbf{H}$, Kemmler G, Hinterhuber $\mathrm{H}_{\text {, }}$ Marksteiner J (2007). Differential effect of catecholO-methyltransferase Val158Met genotype on emotional recognition abilities in healthy men and women. Journal of the International Neuropsychological Society 13, 881-887.

Welham J, Scott J, Williams G, Najman J, Bor W, O'Callaghan M, McGrath J (2009). Emotional and behavioural antecedents of young adults who 
screen positive for non-affective psychosis: a 21-year birth cohort study. Psychological Medicine 39,

625-634.

Whittaker JF, Deakin JF, Tomenson B (2001). Face processing in schizophrenia: defining the deficit. Psychological Medicine 31, 499-507.
Yung AR, Nelson B, Baker K, Buckby JA, Baksheev G, Cosgrave EM (2009). Psychotic-like experiences in a community sample of adolescents: implications for the continuum model of psychosis and prediction of schizophrenia. Australia and New Zealand Journal of Psychiatry 43, 118-128. 